\title{
Monitoring nutrient transport in tissue-engineered grafts
}

Citation for published version (APA):

Liu, J., Hilderink, J., Groothuis, T. A. M., Otto, C., van Blitterswijk, C. A., \& de Boer, J. (2015). Monitoring nutrient transport in tissue-engineered grafts. Journal of Tissue Engineering and Regenerative Medicine, 9(8), 952-960. https://doi.org/10.1002/term.1654

Document status and date:

Published: 01/08/2015

DOI:

10.1002/term. 1654

Document Version:

Publisher's PDF, also known as Version of record

Document license:

Taverne

Please check the document version of this publication:

- A submitted manuscript is the version of the article upon submission and before peer-review. There can be important differences between the submitted version and the official published version of record.

People interested in the research are advised to contact the author for the final version of the publication, or visit the DOI to the publisher's website.

- The final author version and the galley proof are versions of the publication after peer review.

- The final published version features the final layout of the paper including the volume, issue and page numbers.

Link to publication

\footnotetext{
General rights rights.

- You may freely distribute the URL identifying the publication in the public portal. please follow below link for the End User Agreement:

www.umlib.nl/taverne-license

Take down policy

If you believe that this document breaches copyright please contact us at:

repository@maastrichtuniversity.nl

providing details and we will investigate your claim.
}

Copyright and moral rights for the publications made accessible in the public portal are retained by the authors and/or other copyright owners and it is a condition of accessing publications that users recognise and abide by the legal requirements associated with these

- Users may download and print one copy of any publication from the public portal for the purpose of private study or research.

- You may not further distribute the material or use it for any profit-making activity or commercial gain

If the publication is distributed under the terms of Article $25 \mathrm{fa}$ of the Dutch Copyright Act, indicated by the "Taverne" license above, 


\title{
Monitoring nutrient transport in tissue-engineered grafts
}

\author{
Jun Liu ${ }^{1}$, Janneke Hilderink ${ }^{1}$, Tom A.M. Groothuis ${ }^{2}$, Cees Otto ${ }^{2}$, Clemens A. van Blitterswijk ${ }^{1}$ \\ and Jan de Boer ${ }^{1 *}$ \\ ${ }^{1}$ MIRA Research Institute, Department of Tissue Regeneration, University of Twente, Enschede, The Netherlands \\ ${ }^{2}$ MIRA Research Institute, Department of Biophysical Engineering, University of Twente, Enschede, The Netherlands
}

\begin{abstract}
Limited nutrient diffusion in three-dimensional (3D) constructs is a major concern in tissue engineering. Therefore, monitoring nutrient availability and diffusion within a scaffold is an important asset. Since nutrients come in various forms, we have investigated the diffusion of the oxygen, luciferin and dextran molecules within tissue-engineered constructs using optical imaging technologies. First, oxygen availability and diffusion were investigated, using transgenic cell lines in which a hypoxia-responsive element drives expression of the green fluorescent protein gene. Using confocal imaging, we observed oxygen limitation, starting at around $200 \mu \mathrm{m}$ from the periphery in the context of agarose gel with 1 million CHO cells. Diffusion of luciferin was monitored real-time in agarose gels using a cell line in which the luciferase gene was driven by a constitutively active CMV promoter. Gel concentration affected the diffusion rate of luciferin. Furthermore, we assessed the diffusion rates of fluorescent dextran molecules of different molecular weights in biomaterials by fluorescence recovery after photobleaching (FRAP) and observed that diffusion depended on both molecular size and gel concentration. In conclusion, we have validated a set of efficient tools to investigate molecular diffusion of a range of molecules and to optimize biomaterials design in order to improve nutrient delivery. Copyright (c) 2013 John Wiley \& Sons, Ltd.
\end{abstract}

Received 25 September 2012; Accepted 21 October 2012

Keywords tissue engineering; nutrient supply; 3D scaffold; bioluminescent imaging; FRAP; hypoxia

\section{Introduction}

Currently, clinical application of cell-based tissue engineered constructs is limited to tissue sheets or avascular tissues such as bladder, skin and cartilage, because of restricted nutrient supply in larger three-dimensional (3D) constructs, both in vitro and in vivo. Oxygen diffusion in tissue is limited to a distance of 100-200 $\mu \mathrm{m}$ (Carmeliet and Jain, 2000; Malda et al., 2007). In tissue-engineered constructs, cell survival, proliferation and even differentiation largely depend on the availability of oxygen and other nutrients. It was reported that $3 \mathrm{D}$ tissue-engineered constructs display a gradient of nutrients, resulting in heterogenic cell growth in the graft (Kellner et al., 2002;

*Correspondence to: Jan de Boer, Department of Tissue Regeneration, Building Zuidhorst ZH132, Postbus 217, University of Twente, 7500 AE Enschede, The Netherlands.E-mail:j.deboer@tnw.utwente.nl
Lewis et al., 2005). Therefore, understanding the diffusion, distribution and availability of nutrients and growth factors in cell-material constructs is necessary because it is a crucial step in tissue survival and formation.

Due to its low solubility, oxygen is expected to be one of the first nutrients to become limiting and is therefore a critical nutrient in cell survival (Malda et al., 2004a, 2004b). In contrast to the human body, tissue-engineered constructs lack natural vasculature, and supply of oxygen can occur by molecular diffusion only (Radisic et al., 2006). Therefore, oxygen is recognized as a model nutrient, which has been studied extensively using electrodes (Malda et al., 2004a, 2004b), oxygen-quenched luminescence (Kellner et al., 2002), phosphorescence-quenching microscopy (Guaccio et al., 2008) and electron paramagnetic resonance (Ellis et al., 2001). On the other hand, very limited knowledge is available on the availability and diffusion of other nutrients or metabolites (e.g. glucose, lactic acid) in 3D grafts. 
Previously we and others have used transgenic cell lines in which a hypoxia-responsive element (HRE) drives the luciferase gene to study oxygen levels in tissue-engineering systems (Liu et al., 2010) and tumour research (Shibata et al., 2000; Harada et al., 2007). Cells express luciferase in the case of limited oxygen availability, and luciferase activity can be evaluated by bioluminescent imaging or using an enzymatic assay in terms of light intensity. Using HRE-Luc cells, we detected more oxygen deficiency when a $3 \mathrm{D}$ cell-seeded graft was grown in a conventional static culture, as compared to perfused bioreactors. In addition, when the HRE-Luc cell-seeded grafts were implanted subcutaneously in nude mice, strong luciferase activity was observed, indicating a lack of oxygen in vivo. Thus, cells with this reporter system could serve as a non-invasive, quantitative and efficient tool to study oxygen availability.

Besides reporter-based cellular assays, it is also possible to monitor molecular diffusion in real time. Fluorescence recovery after photobleaching (FRAP) has been used to investigate protein diffusion in the cell nucleus, cytoplasm and membranes (Presley et al., 1997; van Royen et al., 2009). This approach, first described in 1976 by Axelrod et al. (1976), involves irreversible photobleaching of fluorescently labelled molecules in a defined region of the specimen by a short and intense laser pulse. The recovery of fluorescence in this area, caused by exchange of bleached and unbleached molecules due to Brownian diffusion, is an indicator of the mobility of the fluorophores. Pinte et al. (2008) reported on the diffusion of polymer additives in food using FRAP, where they demonstrated size-dependent diffusion of food additives. Leddy and Guilak (2003) demonstrated that molecular diffusion depended on molecular size and the zone of articular cartilage in which the molecules were present.

In this study, we have adopted both cell reporter and FRAP technology to investigate molecular diffusion and availability in tissue-engineered constructs.

\section{Materials and methods}

\subsection{Cell culture}

Chinese hamster ovary (CHO) cells (CCL-61; ATTC) were cultured in $\alpha$-MEM medium (Life Technologies) supplemented with 10\% fetal bovine serum (FBS; Cambrex), $2 \mathrm{~mm}$ L-glutamine (Life Technologies), $100 \mathrm{U} / \mathrm{ml}$ penicillin (Life Technologies) and $10 \mu \mathrm{g} / \mathrm{ml}$ streptomycin (Life Technologies). Cells were grown at $37^{\circ} \mathrm{C}$ in a humid atmosphere with $5 \% \mathrm{CO}_{2}$. The medium was refreshed twice a week.

\subsection{Plasmids}

The pHRE-Luc plasmid was kindly provided by Dr Kiyoshi Nose (Showa University, Tokyo, Japan; Shibata et al., 1998; Yamazaki et al., 2003). To create pcDNA3\HRE-GFP, a HindIII/XbaI GFP fragment and the HRE fragment were inserted into pcDNA3 (Promega), from which the CMV promoter had been removed. To create pcDNA3\CMV-Luc2, Luc2 was excised from pGL4 (Promega) and inserted into pcDNA3. Both constructs were sequence-verified.

\subsection{Transfection of the reporter gene and cloning of stable transformants}

CHO cells were transfected with Fugene 6 agent (Roche), both pcDNA3 \HRE-GFP and pcDNA3\CMV-Luc2, and subsequently cultured in medium with $3 \mathrm{mg} / \mathrm{ml} \mathrm{G418}$ (Sigma) for 1 week. Antibiotic-resistant cells were seeded at very low density, and colonies were isolated and tested for luciferase expression or screened for GFP expression.

\subsection{Viability staining}

A staining solution was made of PBS supplemented with $6 \mu \mathrm{M}$ ethidium homodimer and $1 \mu \mathrm{M}$ calcein (Invitrogen) to stain the dead (red) and live (green) cells, respectively. Gel slides with cells were washed in PBS and subsequently stained by covering the samples with staining solution and incubating for $15 \mathrm{~min}$ at $37^{\circ} \mathrm{C}$ in the dark. The samples were visualized by fluorescence microscopy (Nikon Eclipse E600, FITC/Texas red filter).

\subsection{Fluorescent imaging of GFP expression from HRE-GFP cells}

Twenty thousand HRE-GFP CHO cells (HG) cells were seeded in a well of a 96-well plate and incubated with and without $250 \mu \mathrm{M}$ hypoxia-mimicking compound desferrioxamine (DFO) (Bartolome et al., 2009) for $24 \mathrm{~h}$, then fixed in $10 \%$ formalin for $20 \mathrm{~min}$ at room temperature. GFP expression was investigated by confocal fluorescence microscopy, using a $\times 10$ objective (BD pathway 435 ). The obtained images were analysed using Attovision software. DAPI (Dako) was used to stain the cell nuclei.

Agarose gels (Invitrogen) at various concentrations were mixed with 1 million HG cells and were processed into cylinders with dimensions of $4.8 \mathrm{~mm}$ height $\times 4.8 \mathrm{~mm}$ diameter, using a sterile stainless-steel punch with a diameter of $4.8 \mathrm{~mm}$. A viability assay was performed as described above. The gels were cut into $1 \mathrm{~mm}$ slices and fixed in $10 \%$ formalin for $20 \mathrm{~min}$ at room temperature. The gel slices were stained with DAPI and GFP expression from cells was analysed as mentioned above. This experiment was performed in triplicate.

\subsection{Real-time imaging of the luciferase activity in $3 \mathrm{D}$ gel constructs}

CMV-Luc2 (CL2) cells were combined with agarose gel and examined for viability after 1 day, as described above. Bioluminescent imaging (BLI) was performed by incubating the gels in a luciferin (Synchem Chemie) solution in phosphate-buffered saline (PBS; Gibco). Bioluminescence was recorded in real time, using a CCCD camera 
(LN/CCD-1300EB) with a 50 mm F1.2 Nikon lens (Roper Scientific), controlled by Metavue software (Universal Imaging, West Chester, PA, USA). For each image, photons were collected for $1 \mathrm{~min}$. Quantification was performed using Image J software.

\subsection{Diffusion measurements by FRAP}

Stock solutions of fluorescein isothiocyanate (FITC; 389 Da) and three fluorescein-labelled dextrans (3, 10 and $70 \mathrm{kDa}$, Invitrogen) were prepared by dissolving in TE buffer (10 mM Tris-Cl +1 mM EDTA, pH 7.5). Table 1 shows some molecules involved in tissue engineering, encompassing the relevant size range of dextrans. Agarose gels were prepared and before gelation; the viscous agarose was mixed with the dye solution (final dye concentrations, $5 \mu \mathrm{M}$; final agarose concentrations, $0.5 \%, 1 \%$ and $2 \%$ ) and cooled to room temperature to solidify. The gels were cut into slices of approximately $1 \times 4.8 \times 4.8 \mathrm{~mm}$ and mounted on glass coverslides.

FRAP experiments were performed on 5 slices/condition, using a laser-scanning confocal microscope (Zeiss LSM 510) with a $\times 40$ objective and an argon laser. The images $(512 \times 512$ pixels $)$ with a resolution of $0.44 \mu \mathrm{m} /$ pixel were taken in an optical slice of $<6.3 \mu \mathrm{m}$. The $488 \mathrm{~nm}$ laser line was used for illumination and the fluorescence was detected with a $505 \mathrm{~nm}$ longpass filter. Bleaching was performed on a circular region $(r=22 \mu \mathrm{m})$ at $100 \%$ laser intensity during $30 \mathrm{~s}$. Dried samples were used as a positive control to determine the minimal number of iterations needed to completely bleach the selected area. After bleaching, recovery images were recorded with $0.98 \mathrm{~s} / \mathrm{scan}$ until the fluorescent intensity of the bleached region reached a plateau. The average intensity of the bleached area was normalized to the intensity in an unbleached part of the sample, to correct for possible autobleaching, and fractional fluorescence recovery was plotted as:

$$
f_{k}(t)=\frac{f_{R O I}(t) / f_{r e f}(t)-f_{R O I}(0) / f_{r e f}(0)}{f_{R O I}(\infty) / f_{r e f}(\infty)-f_{R O I}(0) / f_{r e f}(0)}
$$

where $f_{R O I}$ is the intensity in the bleached spot and $f_{r e f}$ is the intensity in a region outside the region of interest (ROI) at time $t$, immediately after bleaching $(t=0)$ and after complete recovery $(t=\infty)$. The recovery curve was fitted (GraphPad Prism 5.0) to a one-phase association curve fit:

Table 1. Size comparison of dextrans studied and relevant molecules (see Leddy and Guilak, 2003)

\begin{tabular}{lc}
\hline Molecule & Molecular weight (kDa) \\
\hline Dextran-70 & 70 \\
TGF $\beta$ & 25 \\
BMP-2 & 18 \\
Dextran-10 & 10 \\
Insulin & 5 \\
Dextran-3 & 3 \\
Glucose & 0.18 \\
FITC & 0.389 \\
Luciferin & 0.28 \\
Oxygen & 0.032 \\
\hline
\end{tabular}

$$
f(t)=f_{0}+\left(f_{\text {plateau }}-f_{0}\right) *\left(1-e^{-\frac{1}{\tau} t}\right)
$$

and half-recovery times were obtained from this curve fit by $T_{1 / 2}=\ln 2 * \tau . R^{2}$ values ( $=1$ for a perfect fit) of the curve fit were determined. Diffusion coefficients $(D)$ were calculated by $D=\gamma_{D} \frac{\omega^{2}}{4 \tau_{1 / 2}}$, where $\omega$ is the radius of the ROI disc and $\gamma_{D}$ is the bleaching parameter (Axelrod et al., 1976) for the shape of the laser beam $\left(\gamma_{D}=0.88\right.$ for circular beams). This analysis assumes a two-dimensional (2D) configuration. Since the images are recorded in a thin section of the sample (optical slice $<6.3 \mu \mathrm{m}$ ), diffusion in and out of the imaging plane at the third dimension can be neglected.

Statistical analyses were performed using Student's $t$-test and two-way ANOVA; ${ }^{*} p<0.05,{ }^{* *} p<0.01, * * * p<0.001$.

\section{Results}

\subsection{HRE-GFP reveals progressive hypoxia in $3 D$ TE gels}

We previously described a method of using HRE-Luctransfected cells (HL cells) to investigate the oxygen availability both in vitro and in vivo (Liu et al., 2010). In this study we employed another reporter, GFP, to replace luciferase to study oxygen status in 3D tissue-engineered gel constructs at the individual cell level.

An HRE-GFP CHO cell line (HG) was created, and GFP expression was induced using DFO, a compound known to mimic hypoxia (Figure 1A), demonstrating that the response of this cell line to hypoxia is an increase in GFP expression. When 1 million HG cells were seeded in a $1 \%$ agarose cylinder gel, no GFP was detected after $4 \mathrm{~h}$ but it was highly expressed after $24 \mathrm{~h}$ (Figures 1B, 2A). We quantified the percentage of GFP-positive cells and observed $<10 \%$ of GFP cells after 6 h of incubation, which progressively increased to $30 \%$ within $24 \mathrm{~h}$ (Figure 2B). Interestingly, the GFP-positive cells did not distribute evenly throughout the gel (Figure 1B). More GFP cells were observed in the central part of the gel than at the periphery, where a zone of GFP-negative cells was seen up to $100-200 \mu \mathrm{m}$ from the periphery. Moreover, the GFP expression along the depth to the centre was evaluated and a critical distance around $1000 \mu \mathrm{m}$, where the hypoxia reached the maximum, was noticed (Figure 2C). This observation corresponds well to what we previously reported using an $\mathrm{O}_{2}$ microelectrode sensor (Malda et al., 2004a, 2004b). We did not detect a significant difference in the percentage of GFP cells between different gel densities (Figure 2B).

\subsection{Luciferin as a model molecule for diffusion in $3 \mathrm{D}$ gel construct}

In previous research we employed CMV-Luc2 (CL2) cells for in vivo implantation as an index for cell number, because the CMV promoter is constitutively active. Based 
A

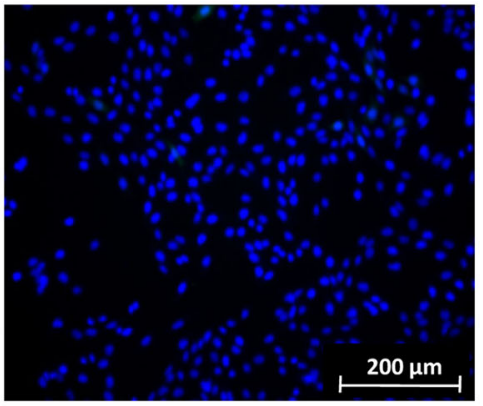

Con

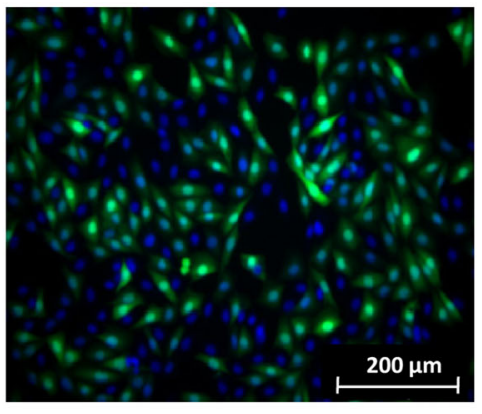

DFO $250 \mu \mathrm{M}$
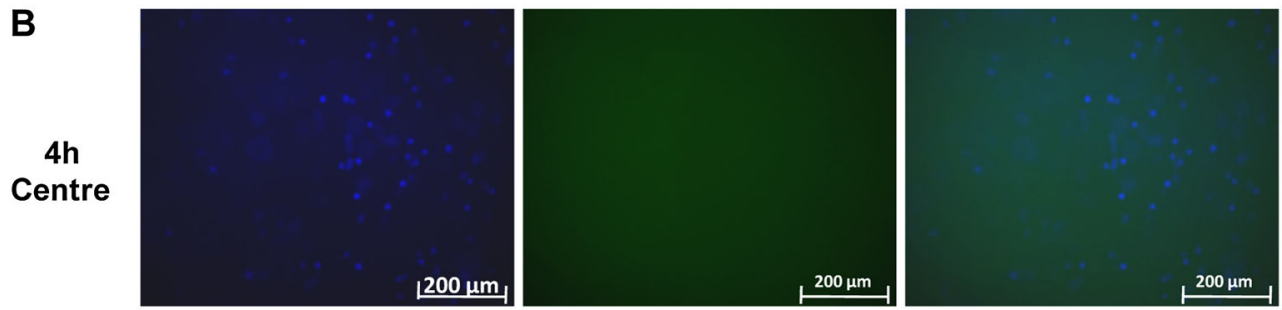

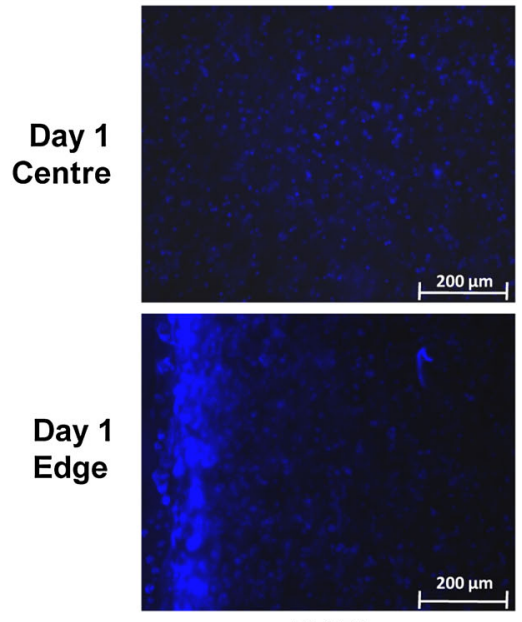

DAPI
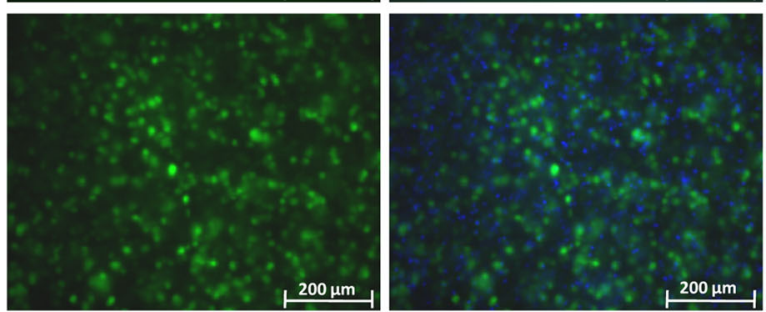

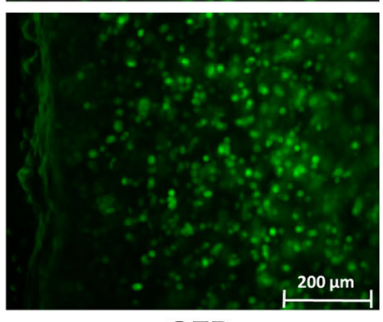

GFP

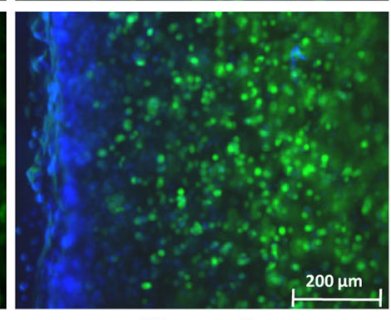

Merged

Figure 1. HRE-GFP CHO cells express GFP in 2D and 3D cultures. (A) DFO-induced GFP expression of HG cells in 2D culture; blue staining, DAPI, which stains the nuclei. (B) Heterogeneous GFP expression (green staining) in HG cells incubated in 3D agarose gel at normoxia after 1 and 2 days, when most cells had died in the centre (not shown)

on this, we used CL2 cells as a model to investigate the molecular diffusion of the luciferin in 3D gel constructs. Different numbers of CL2 cells were incubated in agarose gels of various concentrations for 1 day, and luciferin availability was evaluated in terms of light intensity, using real-time bioluminescent imaging (BLI). Light emission started at the periphery of the gels, correlated to the cell number and increased progressively with time. This exactly reflected the luciferin diffusion out of the constructs (Figure 3A). When luciferin reached a balance between diffusion and consumption, a plateau in light intensity was reached (Figure 3B). However, the dynamically developing curve revealed higher light intensity from gels at low concentrations, where $1 \%$ gel with 3 million cells had a significantly lower light intensity than that from $0.3 \%$ and $0.5 \%$ gels with an equal number of cells, as verified by live/dead staining (Figure 3B, C; data for live/dead staining not shown). This indicated that luciferin diffusion rates depend on gel concentrations. We analysed the slopes of the dynamic curves as a measure of molecular diffusion of luciferin in the gel. Figure 3D clearly demonstrates that luciferin diffusion in $0.3 \%$ agarose gel is 1.12 times faster than that in $0.5 \%$ gel, which is in its turn 1.15 times faster than in 1\% gel. In contrast, the cell number did not affect luciferin diffusion, as evidenced by the good linear fit $\left(R^{2}=0.9986\right)$ of $1 \%$ gels containing 1 million, 3 million and 5.5 million cells, respectively (Figure 3C). Our data show that luciferin can be used as a model molecule to analyse diffusion in biomaterials.

\subsection{Size-dependent molecular diffusion in TE gels}

To expand the molecular sizes of substances of interest, a more direct method was adopted to assess molecular diffusion in biomaterials. It is based on fluorescence recovery after photobleaching (FRAP) of a fluorescent molecule. To this end, fluorescent dextran molecules of different molecular weights were mixed in agarose gels and FRAP 


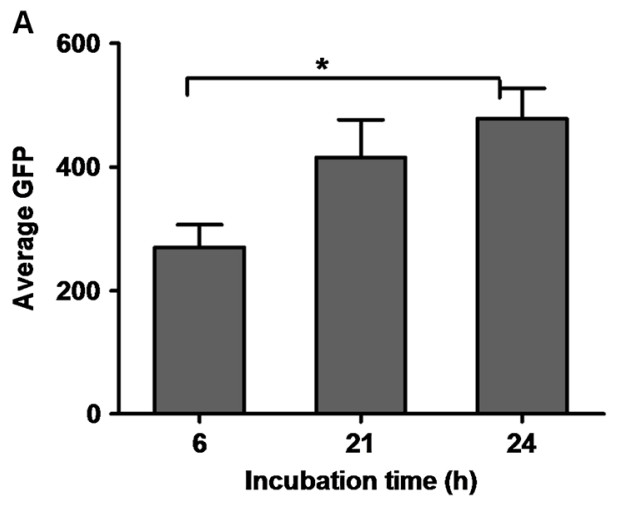

B
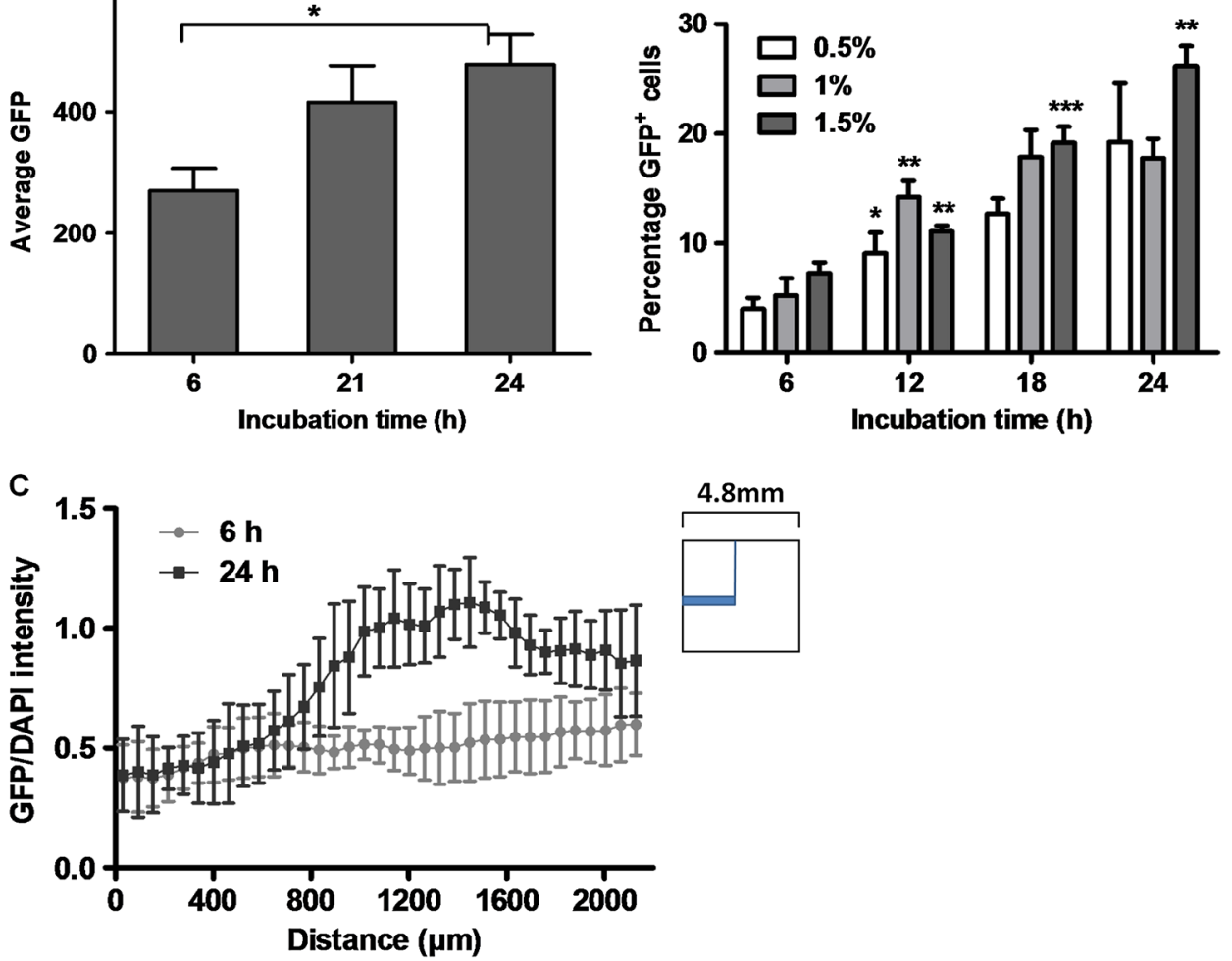

Figure 2. GFP expression increases with time in 3D tissue-engineered grafts. (A) The average GFP intensity throughout a gel slice increases with time; 1 million HG cells were incubated in a 1\% agarose gel. (B) Increase in the number of GFP-positive cells with incubation time; GFP-expressing cells were counted in an area of $4.8 \mathrm{~mm} \times 631 \mu \mathrm{m}$ by confocal fluorescent microscopy. The number of DAPI cells counted/gel slice was around $1.44 \times 10^{4}$. Significant comparison was done by comparing the gel at different time points to the same gel density at the previous time point by two-way ANOVA; ***p $p<0.0001$. (C) Average GFP intensity corrected for cell numbers (DAPI fluorescent intensity) depends on the diffusion distance within the gel; values represent mean \pm SD ( $n=3-5$ )

was performed. Figure 4A depicts the different stages in a FRAP experiment with $70 \mathrm{kDa}$ dextran in a $0.5 \%$ agarose gel. In dried samples, little or no recovery was observed, because the molecules were immobilized due to lack of water. In normal gel samples, the bleaching and recovery of fluorescent signal could be clearly monitored (Figure 4B).

We first assessed the effects of different gel concentrations on molecular diffusion. Figure 5A shows fluorescent recovery during the FRAP process in $0.5 \%, 1 \%$ and $2 \%$ agarose gels with a $70 \mathrm{kDa}$ dye. The calculated half recovery time $\left(T_{1 / 2}\right)$ increased with gel concentrations, indicating a lower diffusion rate in high-concentration gels (Figure 5B). Additionally, different dye concentrations did not affect $T_{1 / 2}$, demonstrating that the diffusion rate, $D$, is a property of the material and independent of the dye concentration (Table 2). Interestingly, when doubling the gel concentration, there is a change in $T_{1 / 2}$ with a factor of 1.14 (Figure 5B), which is the same as observed in Figure 3D.

Next, we performed FRAP experiments with dextrans of different molecular weights and the $T_{1 / 2}$ values were calculated. The dynamic curves in Figure $6 \mathrm{~A}$ and the corresponding $T_{1 / 2}$ values (Figure $6 \mathrm{~B}$ ) showed that bigger molecules have higher $T_{1 / 2}$ values, indicating lower mobility. Intriguingly, increasing the molecular size from 10 to $70 \mathrm{kDa}$, for example, led to a more than 2.7-times slower recovery. Again, the effect of the density of the gel on the mobility of the particles was observed. Table 3 summarizes the diffusion coefficients based on the $T_{1 / 2}$ values.

\section{Discussion}

Previously, we have employed oxygen as a model molecule to monitor nutrient availability for cells in tissueengineered constructs, both in vitro and in vivo (Liu et al., 2010). We found that oxygen was sufficient only to cells at the periphery of tissue-engineered constructs in conventional static culture, where nutrient provision depends solely on diffusion (van Blitterswijk et al., 2008). Nutrient availability is determined by both nutrient diffusion and cellular consumption, and diffusion, in its turn, is determined by material properties, particle properties and the presence of matrix or cells. In this study we were interested in investigating the nutrient transport (diffusion) in tissue-engineered constructs using both an indirect method, in which reporter genes respond to the absence of oxygen and presence of luciferin, and direct methodology to measure molecular diffusion, i.e. FRAP. We investigated the effect of material properties on diffusion and nutrient availability.

The indirect method is based on activation of a certain reporter gene driven by regulatory genetic elements, 


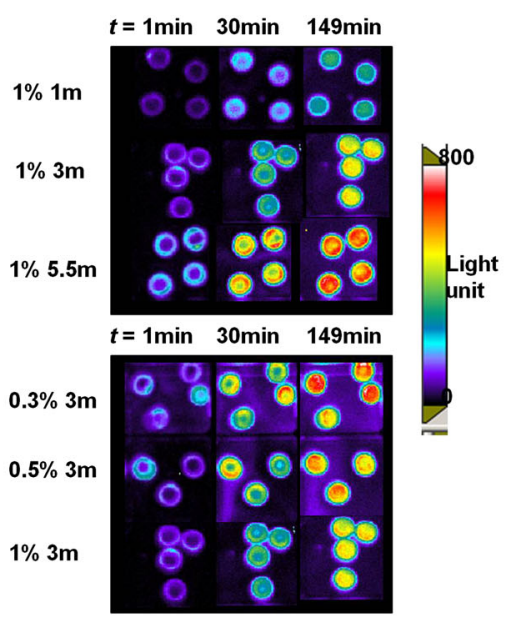

C

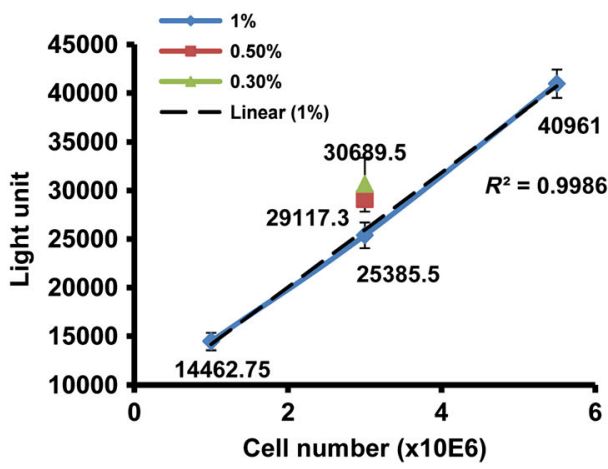

B
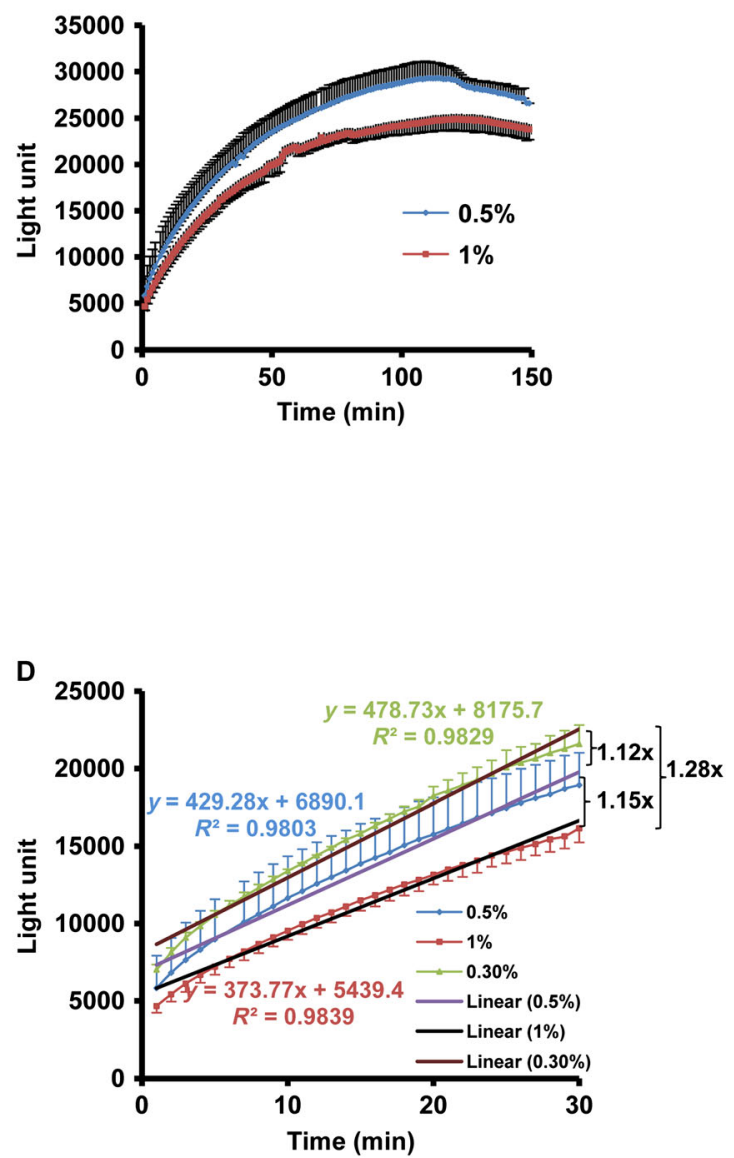

Figure 3. Limited luciferin diffusion in hydrogels. (A) Luciferin diffusion in agarose gels with time (1, 30 and $149 \mathrm{~min}) ; 4.8 \mathrm{~mm}$ diameter cylindrical gels included 1 million $(1 \mathrm{~m}), 3$ million $(3 \mathrm{~m})$ and 5.5 million $(5.5 \mathrm{~m})$ CL2 cells at different agarose concentrations. Pseudocolour represents light intensity, and each image was taken for $1 \mathrm{~min}$. (B) Dynamic analysis of luciferase expression from agarose gels containing 3 million cells revealed a difference in diffusion behaviour of luciferin depending on gel concentration. (C) Plateau light intensities produced by CL2 cells in gels of different concentration $(0.3 \%, 0.5 \%$ and $1 \%)$ or different numbers of cells: black line represents linear fit; $R^{2}$ represents the the curve fit. (D) The slopes and their curve-fits from dynamic analysis of luciferase expression from the above gels revealed gel concentration-dependent diffusion; values represent mean \pm SD ( $n=3-4)$

A

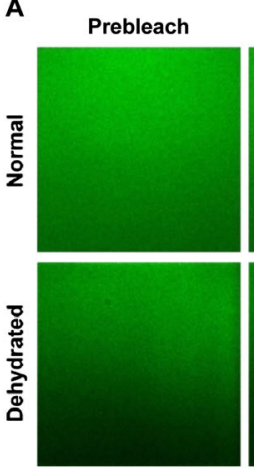

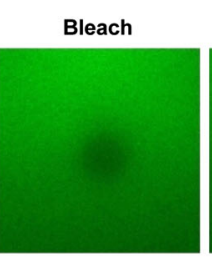

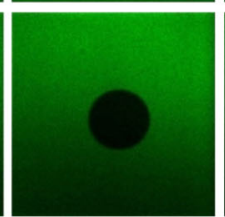

Recovery

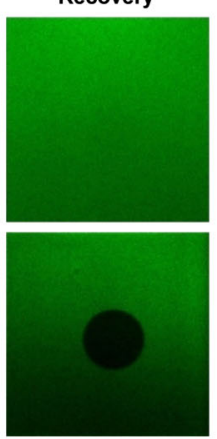

B

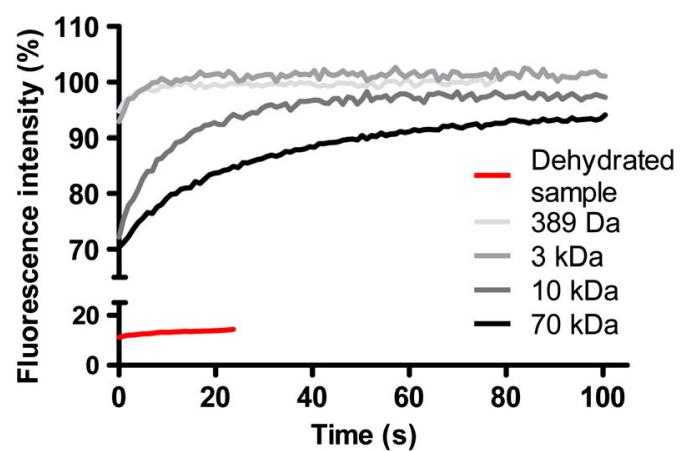

Figure 4. FRAP imaging of molecular diffusion in hydrogels. (A) Different phases of FRAP using a $70 \mathrm{kDa}$ dextran-FITC dye (from left to right) in normal and dehydrated $0.5 \%$ agarose (control). (B) Recovery curves of DexF dyes and dehydrated control. The quantitative recovery of the fluorescent signal is visualized by plotting the average intensity of the bleached area $\left(f_{\text {ROI }}\right)$ normalized to the background intensity $\left(f_{\text {ref }}\right)$ vs time

which are activated depending on the presence or absence of biologically relevant molecules. We used the hypoxiaresponsive element to measure HIF1 activity, which depends on the level of oxygen in the cell. Using
HRE-GFP-transfected CHO cells, we observed that sufficient oxygen was present for up to $100-200 \mu \mathrm{m}$ in a 3D agarose gel, which corresponds well with the distance reported to be the limit of diffusion in the body (Moldovan 2005). 

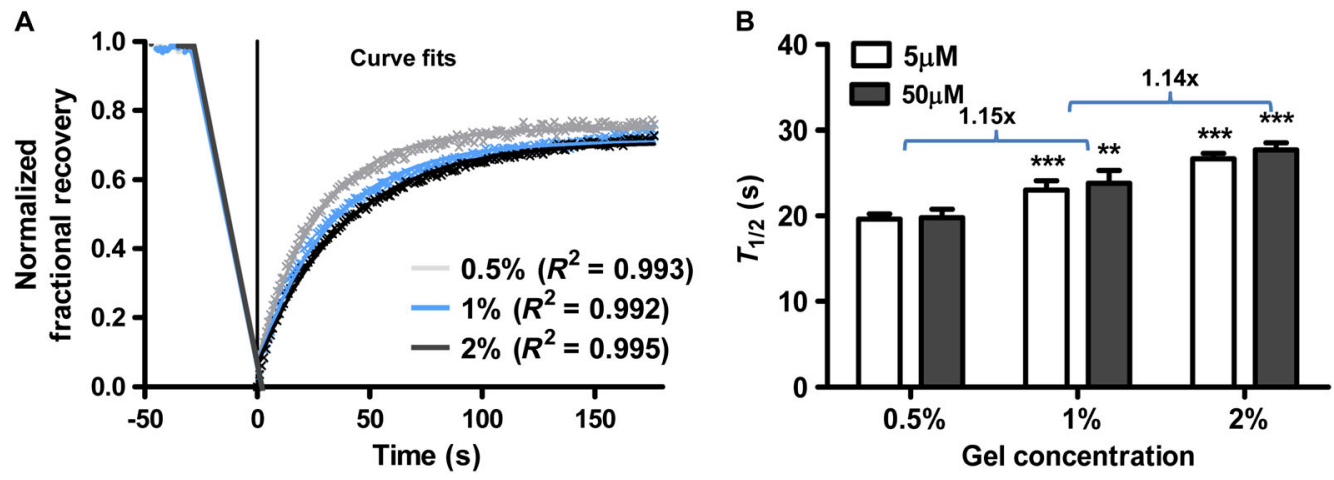

Figure 5. The influence of gel concentration and dye concentration on molecular diffusion. (A) FRAP curves and curve fits of $70 \mathrm{kDa}$ DexF in different agarose gel concentrations; dots represent experimental data and lines are the curve-fits. (B) Half recovery times of DexF dye (MW $70 \mathrm{kDa}$ ) at two different concentrations in agarose gels with three different concentrations; values represent mean $\pm S D(n=3-5)$. Gel concentration had a significant effect on $T_{1 / 2} ; * p<0.01$, while dye concentration did not, which was analysed by two-way ANOVA. Statistical significance of $T_{1 / 2}$ values is calculated relative to the same dye concentration in the previous gel density

Table 2. Effect of dye concentration on diffusion coefficient (D) $\left(\mu \mathrm{m}^{2} / \mathrm{s}\right)$

\begin{tabular}{lcc}
\hline & \multicolumn{2}{c}{ Dye concentration $(\mu \mathrm{M})$} \\
\cline { 2 - 3 } Agarose gel (\%) & 5 & 50 \\
\hline 0.5 & $5.5 \pm 0.2$ & $5.4 \pm 0.3$ \\
1 & $4.7 \pm 0.2$ & $4.5 \pm 0.3$ \\
2 & $4.0 \pm 0.1$ & $3.9 \pm 0.1$ \\
\hline
\end{tabular}

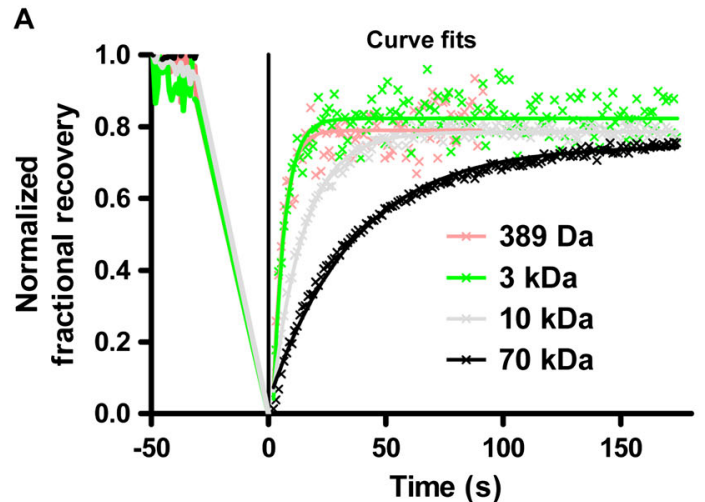

This observation corresponds well with oxygen measurements performed in the past (Malda et al., 2004a, 2004b). Our data show that the HRE-GFP reporter has the right sensitivity to detect hypoxia in 3D constructs and may be used in strategies to improve the availability of oxygen inside the scaffold, e.g. by the use of oxygen-releasing scaffolds (Radisic et al., 2005; Khattak et al., 2007) or by smart design of the scaffold architecture.

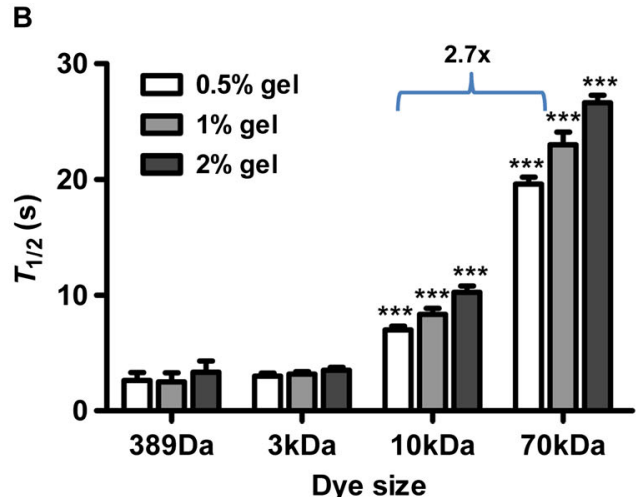

Figure 6. The diffusion rates of dextrans in agarose gels. (A) FRAP curves and curve fits of different-sized dyes in 1\% agarose gels; dots represent experimental data and lines are the curve-fits; $R^{2}=0.811$ for 389 Da dye; 0.790 for $3 \mathrm{kDa}$; 0.984 for $10 \mathrm{kDa}$; 0.992 for $70 \mathrm{kDa}$. (B) Half recovery times of dextrans in different agarose gel concentrations; values represented mean \pm SD ( $n=3-5)$. Statistical analysis was performed by two-way ANOVA. Statistically significant changes in $T_{1 / 2}$ values were calculated by comparing with those of FITC dye (389 Da) in the same gel density

Table 3. Effect of dye size on diffusion coefficient $(D)\left(\mu \mathrm{m}^{2} / \mathrm{s}\right)$

\begin{tabular}{lrccc}
\hline & \multicolumn{5}{c}{ Dye size $(\mathrm{kDa})$} \\
\cline { 2 - 5 } Agarose gel (\%) & \multicolumn{1}{c}{0.389} & \multicolumn{1}{c}{3} & \multicolumn{1}{c}{10} & \multicolumn{1}{c}{70} \\
\hline 0.5 & $42.4 \pm 12.0$ & $35.6 \pm 3.1$ & $15.2 \pm 0.7$ & $5.5 \pm 0.2$ \\
1 & $45.32 \pm 13.6$ & $33.5 \pm 2.2$ & $12.8 \pm 0.8$ & $4.7 \pm 0.2$ \\
2 & $29.4 \pm 12.6$ & $30.4 \pm 2.0$ & $10.4 \pm 0.5$ & $4.0 \pm 0.1$ \\
\hline
\end{tabular}

Furthermore, we observed a gradual increase in GFP expression from the periphery to the interior of the gel, demonstrating a gradient of oxygen availability in the construct.
We also want to point out that the promotor-reporter strategy is very flexible, because the promoter can be tailored to detect the availability of other molecules of interest in tissue-engineered grafts. For instance, the presence and biological activity of bone morphogenetic protein (BMP) can be evaluated by using a BMP-responsive element as genetic element driving GFP expression (Monteiro et al., 2004). In this study we used the CMV-luciferase reporter to study diffusion of substrate luciferin in the context of tissue engineering. We clearly showed the dynamic process of luciferin diffusion by detecting in real time the increasing light intensity when the luciferin substrate is added to an agarose gel seeded with 
CMV-Luc2 transgenic cells. The slope of the dynamic light intensity demonstrated that the higher gel concentration leads to a more limited luciferin diffusion. Surprisingly, the plateau of light intensity was lower for the highpercentage gels than for low-percentage gels, although we anticipated that the molecular equilibrium would have been the same. We think that the observed difference in the plateaux of light intensity is caused by the consumption of luciferin by the cells, which created a source-sink correlation between luciferin in the medium and luciferin in the interior of the construct. At higher gel concentrations, with limited diffusion but equal consumption capacity by the cells, luciferin diffusion becomes rate-limiting and hence the plateau is lower. However, higher light intensity meant more luciferin consumption and less luciferin available, which reversely affected the light intensity in a $0.5 \%$ gel sample at the time of 120-150 min after imaging.

Differences in diffusion properties can also be monitored directly by visualizing fluorescent proteins instead of enzymatically converted substrates, using the FRAP method. We used fluorescently labelled dextrans in a molecular weight range representing small molecules such as oxygen, intermediate size molecules such as glucose and lactate, and large-sized proteins. We observed that the diffusion rate in agarose gels depend both on gel concentration and molecular weight of the dextrans, but was independent of the concentration of the fluorescent dextrans. The diffusion rates measured in our report are in the same magnitude $\left(10^{-11} / \mathrm{m}^{2} / \mathrm{s}\right)$ as published previously (Roger et al., 2000). We acknowledge the fact that the agarose system used is a simplified representation of the real extracellular matrices in the body or tissue-engineered constructs. Nevertheless, we have demonstrated that FRAP is a very useful tool that can be used to screen for biomaterial chemistries or architecture that favours molecular diffusion. Improving molecular diffusion is an important step towards modelling, and eventually improving, the transport of nutrients or certain growth factors in tissue-engineering constructs.

During the experiments, we noted that the bleaching process in the normal samples was not as efficient as in the dehydrated samples, and that the bleaching efficiency for the bigger dyes was higher than for the smaller dyes. This can be explained by the recovery during photobleaching process. The intensities of the $389 \mathrm{Da}$ and $3 \mathrm{kDa}$ dyes were only decreased with $5 \%$ and $8 \%$, respectively, of the initial fluorescence, while bleaching the $10 \mathrm{kDa}$ and $70 \mathrm{kDa}$ dyes resulted in a 30\% fluorescence drop. The small amount of bleaching of the small dyes (389 Da and $3 \mathrm{kDa}$ ) results in less accurate curve fits, and thus less accurate $T_{1 / 2}$ values and diffusion coefficients.

In this manuscript, we have monitored the availability and diffusion of model nutrients in cell-biomaterial 3D constructs. In conclusion, we have demonstrated that optical imaging with reporter genes is a versatile tool to study nutrient or growth factor availability in 3D tissueengineered constructs, and we clearly demonstrated that optical imaging in tissue engineering exceeds merely visualizing cells or differentiation. FRAP could provide direct knowledge on nutrient diffusion in biomaterials. Combined with appropriate cellular assays, it can also be very useful to evaluate biomaterial properties to optimize scaffold structural design and modification to improve the nutrient or growth factors provision to cells.

\section{Acknowledgements}

We thank Dr Shinae Kizaka Kondoh from Kyoto University, Kyoto, Japan, for providing the HRE-Luc plasmid DNA. This research was sponsored by a grant from Senter/Novem.

\section{References}

Axelrod D, Koppel DE, Schlessinger J, et al. 1976; Mobility measurement by analysis of fluorescence photobleaching recovery kinetics. Biophys J 16: 1055-1069.

Bartolome S, Dhillon NK, Buch S, et al. 2009; Deferoxamine mimics the pattern of hypoxiarelated injury at the microvasculature. Shock 31: 481-485.

Carmeliet P, Jain RK. 2000; Angiogenesis in cancer and other diseases. Nature 407: 249-257.

Ellis SJ, Velayutham M, Velan SS, et al. 2001; EPR oxygen mapping (EPROM) of engineered cartilage grown in a hollow-fiber bioreactor. Magn Reson Med 46: 819-826.

Guaccio A, Borselli C, Oliviero O, et al. 2008; Oxygen consumption of chondrocytes in agarose and collagen gels: a comparative analysis. Biomaterials 29: 1484-1493.

Harada H, Kizaka-Kondoh S, Itasaka S, et al. 2007; The combination of hypoxia-response enhancers and an oxygen-dependent proteolytic motif enables real-time imaging of absolute HIF-1 activity in tumor xenografts. Biochem Biophys Res Commun 360: 791-796.
Kellner K, Liebsch G, Klimant I, et al. 2002; Determination of oxygen gradients in engineered tissue using a fluorescent sensor. Biotechnol Bioeng 80: 73-83.

Khattak SF, Chin KS, Bhatia SR, et al. 2007; Enhancing oxygen tension and cellular function in alginate cell encapsulation devices through the use of perfluorocarbons. Biotechnol Bioeng 96: 156-166.

Leddy HA, Guilak F. 2003; Site-specific molecular diffusion in articular cartilage measured using fluorescence recovery after photobleaching. Ann Biomed Eng 31: 753-760.

Lewis MC, Macarthur BD, Malda J, et al. 2005; Heterogeneous proliferation within engineered cartilaginous tissue: the role of oxygen tension. Biotechnol Bioeng 91: 607-615.

Liu J, Barradas A, Fernandes H, et al. 2010; In vitro and in vivo bioluminescent imaging of hypoxia in tissue-engineered grafts. Tissue Eng Part C Methods 16: 479-485.

Malda J, Klein TJ, Upton Z. 2007; The roles of hypoxia in the in vitro engineering of tissues. Tissue Eng 13: 2153-2162.
Malda J, Rouwkema J, Martens DE, et al. 2004a; Oxygen gradients in tissueengineered PEGT/PBT cartilaginous constructs: measurement and modeling. Biotechnol Bioeng 86: 9-18.

Malda J, Woodfield TB, van der Vloodt F, et al. 2004b; The effect of PEGT/PBT scaffold architecture on oxygen gradients in tissue engineered cartilaginous constructs. Biomaterials 25: 5773-5780.

Moldovan NI. 2005; Angiogenesis, l'enfant terrible of vascular biology, is coming of age. J Cell Mol Med 9: 775-776.

Monteiro RM, de Sousa Lopes SM, Korchynskyi O, et al. 2004; Spatio-temporal activation of Smad1 and Smad5 in vivo: monitoring transcriptional activity of Smad proteins. J Cell Sci 117: 4653-4663.

Pinte J, Joly C, Ple K, et al. 2008; Proposal of a set of model polymer additives designed for confocal FRAP diffusion experiments. J Agric Food Chem 56: 10003-10011.

Presley JF, Cole NB, Schroer TA, et al. 1997; ER-to-Golgi transport visualized in living cells. Nature 389: 81-85. 
Radisic M, Deen W, Langer R, et al. 2005; Mathematical model of oxygen distribution in engineered cardiac tissue with parallel channel array perfused with culture medium containing oxygen carriers. Am J Physiol Heart Circ Physiol 288: H1278-1289.

Radisic M, Malda J, Epping E, et al. 2006; Oxygen gradients correlate with cell density and cell viability in engineered cardiac tissue. Biotechnol Bioeng 93: 332-343.

Roger P, Mattisson C, Axelsson A, et al. 2000; Use of holographic laser interferometry to study the diffusion of polymers in gels. Biotechnol Bioeng 69: 654-663.

Shibata T, Akiyama N, Noda $\mathrm{M}$, et al. 1998; Enhancement of gene expression under hypoxic conditions using fragments of the human vascular endothelial growth factor and the erythropoietin genes. Int $J$ Radiat Oncol Biol Phys 42: 913-916.

Shibata T, Giaccia AJ, Brown JM. 2000; Development of a hypoxia-responsive vector for tumor-specific gene therapy. Gene Ther 7: 493-498. van Blitterswijk CA, Williams DF, Lindahl A, et al. 2008; Cell nutrition. In Tissue Engineering, Malda J, Radisic M, Levenberg S, et al. (eds). Elsevier: Amsterdam; 327-362.

van Royen ME, Farla P, Mattern KA, et al. 2009; Fluorescence recovery after photobleaching (FRAP) to study nuclear protein dynamics in living cells. Methods Mol Biol 464: 363-385.

Yamazaki Y, Egawa K, Nose K, et al. 2003; HIF-1-dependent VEGF reporter gene assay by a stable transformant of $\mathrm{CHO}$ cells. Biol Pharm Bull 26: 417-420. 